\title{
Dynamic Behavior of a Flexible Multi-Column FOWT in Regular Waves
}

\author{
Taisuke Takata ${ }^{1}$, Mayuko Takaoka ${ }^{1}$, Rodolfo T. Gonçalves ${ }^{1, *} \mathbb{D}$, Hidetaka Houtani ${ }^{1}{ }^{\mathbb{D},}$, Yasuo Yoshimura $^{1}$, \\ Kentaro Hara ${ }^{2}$, Sho $\mathrm{Oh}^{3}{ }^{3}$, Raúl Dotta ${ }^{4,5}$, Edgard B. Malta ${ }^{5}$, Kazuhiro Iijima ${ }^{2}(1)$ and Hideyuki Suzuki ${ }^{1}$ \\ 1 OSPL—Ocean Space Planning Laboratory, Department of Systems Innovation, The University of Tokyo, \\ Tokyo 113-8656, Japan; taisuke.takata.edu@gmail.com (T.T.); takaoka@g.ecc.u-tokyo.ac.jp (M.T.); \\ houtani@sys.t.u-tokyo.ac.jp (H.H.); yoshimura@orca.t.u-tokyo.ac.jp (Y.Y.); suzukih@sys.t.u-tokyo.ac.jp (H.S.) \\ 2 Ship Structure Integrity Subarea, Department of Naval Architecture and Ocean Engineering, \\ Osaka University, Osaka 565-0871, Japan; kentaro_hara@naoe.eng.osaka-u.ac.jp (K.H.); \\ iijima@naoe.eng.osaka-u.ac.jp (K.I.) \\ 3 ClassNK—Nippon Kaiji Kyokai, Tokyo 102-8567, Japan; s-oh@classnk.or.jp \\ 4 TPN-Numerical Offshore Tank Laboratory, Department of Naval Architecture and Ocean Engineering, \\ University of São Paulo, São Paulo 05508-030, Brazil; rdotta@technomar.com.br \\ 5 Technomar Engenharia Oceânica, São Paulo 05419-905, Brazil; edgard@technomar.com.br \\ * Correspondence: goncalves@g.ecc.u-tokyo.ac.jp; Tel.: +81-3-5841-0480
}

check for updates

Citation: Takata, T.; Takaoka, M.; Gonçalves, R.T.; Houtani, H.; Yoshimura, Y.; Hara, K.; Oh, S.; Dotta, R.; Malta, E.B.; Iijima, K.; et al. Dynamic Behavior of a Flexible Multi-Column FOWT in Regular Waves. J. Mar. Sci. Eng. 2021, 9, 124. https://doi.org/10.3390/jmse9020124

Academic Editor: José A. F. O. Correia Received: 18 December 2020

Accepted: 8 January 2021

Published: 27 January 2021

Publisher's Note: MDPI stays neutral with regard to jurisdictional claims in published maps and institutional affiliations.

Copyright: (c) 2021 by the authors. Licensee MDPI, Basel, Switzerland. This article is an open access article distributed under the terms and conditions of the Creative Commons Attribution (CC BY) license (https:// creativecommons.org/licenses/by/ $4.0 /)$.

\begin{abstract}
A tank experiment using a flexible multi-column floating offshore wind turbine (FOWT) model in regular waves was carried out to clarify the floater elastic response and its influence on the floater motion. The model motion response from the experiment was compared with the numerical simulations by NK-UTWind and WAMIT codes. The dynamic elastic deformation of the model was also compared between the experiment and NK-UTWind. The experiment observed significant elastic deformation for the decks and columns of the model around the wave period corresponding to the natural period of the structural vibration. Furthermore, comparing the heave response amplitude operator (RAO) between experiments and numerical simulations, a small peak appeared around this period in the experiment and NK-UTWind simulation instead of WAMIT simulation. These results indicated that dynamic elastic deformation affected the heave response of the model. The change in the model rigidity revealed that such elastic deformation could affect the motion response statistics in an actual sea condition if the peak period of the onsite wave spectrum is close to the floater natural vibration period. These investigations indicated the importance of considering the elastic behavior of a FOWT at its design stage.
\end{abstract}

Keywords: floating offshore wind turbine (FOWT); elastic characteristics; deformation; wave tests

\section{Introduction}

Offshore wind turbines have been highly expected to play an essential role in power supply. Their advantages are the availability of more substantial and more consistent winds, less noise, and visual pollution than the prevailing onshore wind turbines. In Europe, bottom-mounted types, which can be suitable for shallow seabed sites with a water depth of less than $50 \mathrm{~m}$ [1], have already been widely installed. On the other hand, in the area where water depth increases as it gets far from the shore, floating offshore wind turbines (FOWT) can be preferable.

The bottleneck in the prevalence of FOWT lies in their high costs, especially for installation, operation and maintenance (O and $\mathrm{M})$ [2]. Various floater types of FOWT have been researched to meet the demand for wind energy production in the seas. In Japan, where FOWT is estimated to have a substantial potential for power generation, several types of research have been undertaken at the initiative of the New Energy and Industrial Technology Development Organization (NEDO); such as a barge type at Kitakyushu [3-6], semi-submersibles [7-10], and spar types at Fukushima [11,12]. 
One effective way for their cost reduction is to design compact and light-weight floater, enabled by downsizing the external diameter or thickness of constructional elements. In this case, the elastic deformation of the elements will be profound and need to be discussed concerning structural stability and durability. As an example of a new concept for flexible floaters, a research of a guy-wired supported-tower FOWT can be found in [10,13], suggesting FOWT with guy wires can be the right candidate for further cost reduction.

In general, ocean floating structures can be designed based on the evaluation of hydrodynamic forces by the linear potential theory and structural response by the linear finite element method (FEM). Therefore, motion responses can be discussed by frequency domain and statistical analysis. However, regarding FOWT, because of its severe setting conditions of wind, wave, and current with large fluctuation and turbulence, it is necessary to evaluate floater characteristics with coupled analysis with rotor-floater-mooring involved. Coupled analysis programs, such as Bladed by DNV-GL [14] and FAST by National Renewable Energy Laboratory (NREL) [15], have different characteristics in the modeling of the system dynamic, moorings, aerodynamics, and hydrodynamic forces. The calculation accuracy of these programs has been evaluated and improved compared to the results of water tank experiments as a project of OC5 organized by the International Energy Agency (IEA). This project reveals that each analysis code has different tendencies when calculating the results of motion and structural responses [16]. Furthermore, the tank experiments have mainly focused on the behavior of a rigid floating model or a rigid floating model with flexible tower and blades [17]; the effects of floater flexibility on the dynamic behavior of a FOWT has thus not been investigated.

From these kinds of circumstances, an extremely flexible multi-column model was designed for a water tank experiment, totally different from conventional rigid types. This research aims to reveal its elastic response effect and impacts on the dynamic behavior of the floater. The applicability of NK-UTWind [18] and WAMIT [19] code as a design tool for such a flexible model is verified. Wind loads or water current should be considered in real cases. Still, the focus was on the motion behavior and elastic characteristics of a floater under regular waves with no wind loads in the present research.

\section{Experimental Setup}

\subsection{Reduced Scale Model}

The model designed for the experiment was $1 / 50$ scale of the supposed full-scale FOWT, which is a representative multi-column floater. Footings at the column bottom were designed as spheres instead of circular cylinders used in most research cases to avoid additional damping effects deriving from vortex shedding and to promote intense elastic deformation of the model; see the detailed dimensions in Figure 1.

Core stainless (SUS304) beams were used to represent the model elastic similarity (provide the structural rigidity), and the urethane pieces were wrapped around the core beams to define the geometry similarity. Urethane parts were segmented to avoid additional stiffness. A picture of the reduced scale model is shown in Figure 2.

The Froude law, as shown in Table 1, was applied to this experiment. The main dimensions and properties of the floater are shown in Tables 2 and 3, respectively. Moment of inertia of area, I, was decided, considering Young's modulus, E, in model scale and in full scale, which enabled the model to meet the scale factor of bending rigidity, EI. B, K, G, and $\mathrm{M}$ are defined as the center of floatation, keel, the center of gravity, and metacenter points. 

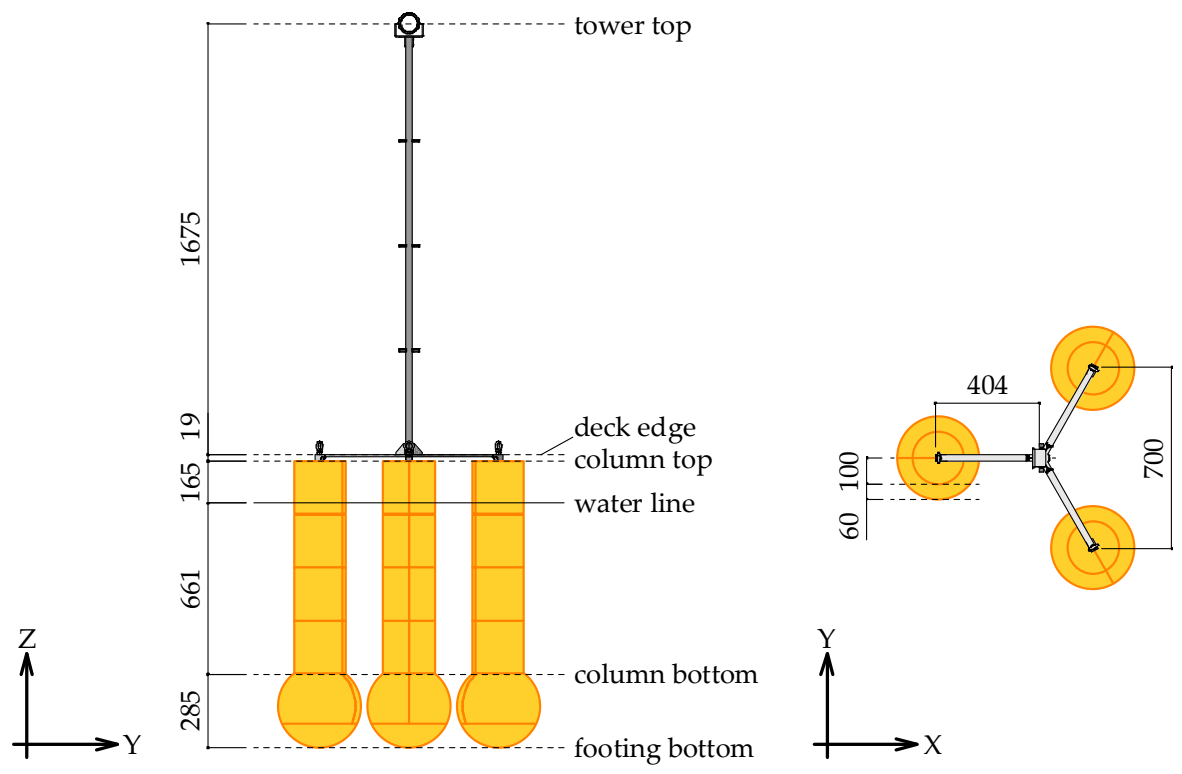

Figure 1. Main dimensions of the reduced scale model.

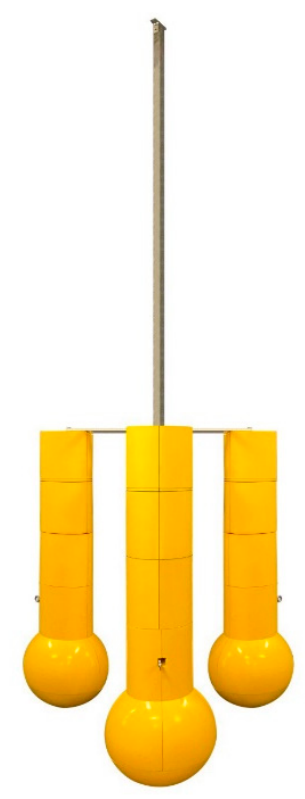

Figure 2. Picture of the reduced scale model.

Table 1. Scale factors using Froude scaling.

\begin{tabular}{cc}
\hline Characteristic & Scale Factor \\
\hline length $[\mathrm{m}]$ & $\lambda$ \\
time $[\mathrm{s}]$ & $\lambda^{\frac{1}{2}}$ \\
force $[\mathrm{N}]$ & $\lambda^{3}$ \\
mass $[\mathrm{kg}]$ & $\lambda^{3}$ \\
flexural rigidity $E I\left[\mathrm{Nm}^{2}\right]$ & $\lambda^{5}$ \\
\hline
\end{tabular}


Table 2. Main dimensions of the floater.

\begin{tabular}{ccc}
\hline Dimension & Prototype Full Scale & Model Scale (1/50) \\
\hline height to the nacelle center & $140.3 \mathrm{~m}$ & $2805 \mathrm{~mm}$ \\
breadth & $51.0 \mathrm{~m}$ & $1020 \mathrm{~mm}$ \\
draft & $47.3 \mathrm{~m}$ & $946 \mathrm{~mm}$ \\
distance between column centers & $35.0 \mathrm{~m}$ & $700 \mathrm{~mm}$ \\
\hline
\end{tabular}

Table 3. Main properties of the floater.

\begin{tabular}{ccc}
\hline Property & Prototype Full Scale & Model Scale 1/50 \\
\hline displacement & $13,934 \mathrm{ton}$ & $111.47 \mathrm{~kg}$ \\
KB & $20.0 \mathrm{~m}$ & $400 \mathrm{~mm}$ \\
BM (roll/pitch) & $3.5 \mathrm{~m}$ & $70 \mathrm{~mm}$ \\
KG & $16.8 \mathrm{~m}$ & $336 \mathrm{~mm}$ \\
GM (roll/pitch) & $6.2 \mathrm{~m}$ & $123 \mathrm{~mm}$ \\
E core material & $2.06 \times 10^{11} \mathrm{~Pa}$ & $1.93 \times 10^{11} \mathrm{~Pa}$ \\
water depth & $110.0 \mathrm{~m}$ & $2200 \mathrm{~mm}$ \\
\hline
\end{tabular}

\subsection{Wave Tank Setup}

All the experiments were carried out in a towing tank at the University of Tokyo (UTokyo), Japan, with $85.0 \mathrm{~m} \times 3.5 \mathrm{~m} \times 2.4 \mathrm{~m}$ (length $\times$ width $\times$ depth). The model was installed $20.0 \mathrm{~m}$ away from the wave generator. Two horizontal moorings composed of wires and springs were aligned to the wave direction and attached to the model to prevent it from drifting. Details of the experimental setup and spring properties are shown in Figure 3 ; where, $\mathrm{k}$ is the spring constant, $\mathrm{T}_{0}$ is the initial tension, and $\mathrm{l}_{0}$ is the natural length of the spring.

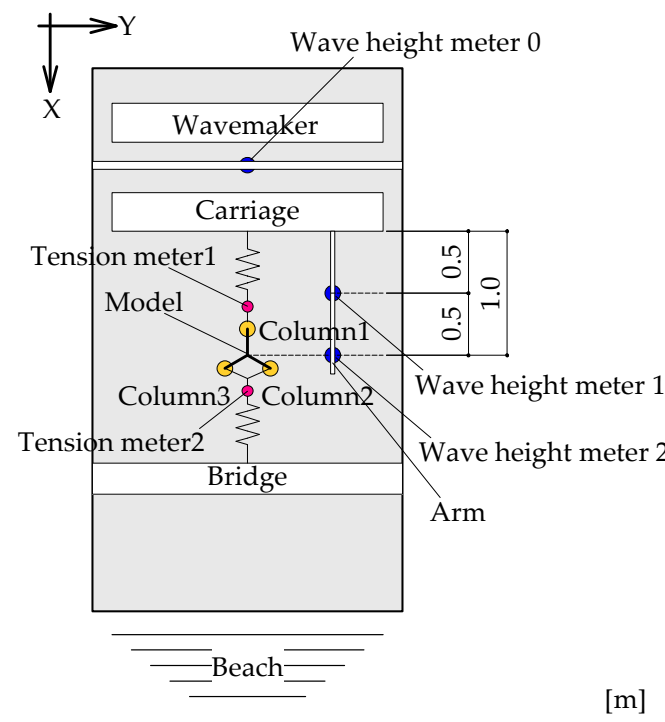

(a)

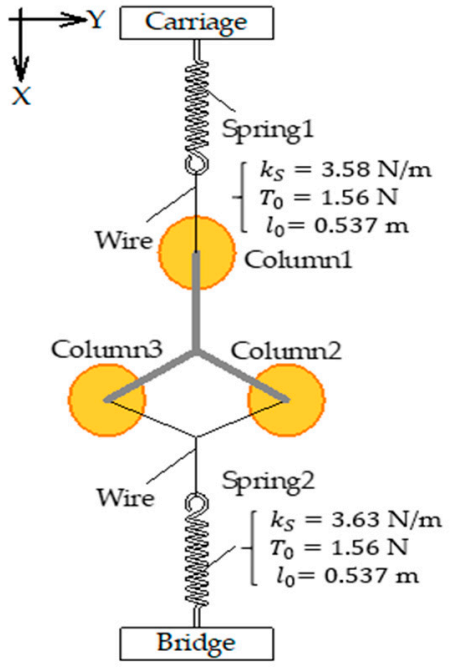

(b)

Figure 3. Experimental setup: (a) top view of the experimental setup in the towing tank; (b) details of the top view of the mooring line settings.

In the wave experiments, 6 degree-of-freedom (DOF) motions of the model and the incident wave were measured. The floating body motions were measured by the Qualysis ${ }^{\circledR}$ Optical Motion Capture System (Qualisys AB, Göteborg, Sweden) comprised of 4 cameras. The wave probe was installed at an intermediate point between the wave generator and the 
experimental model. The waves were calibrated without the model in the position where the model had previously been positioned.

The 6DOF rigid body motions of the model were defined as the motion of the center of gravity.

The model was equipped with twenty-two pairs of strain gauges to measure the bending moment of the tower, decks, and columns. The locations of strain gauges in global coordinates are indicated as blue markers in Figure 4. Gauges 1 to 4 are attached to the tower center, deck base, column base, and column center, respectively. The sampling frequency during the experiments was $100 \mathrm{~Hz}$.

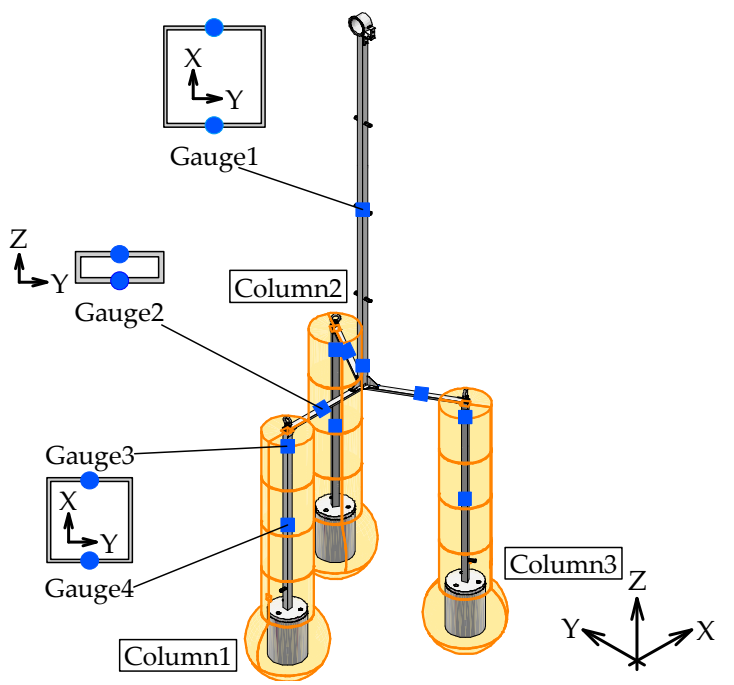

Figure 4. Location of the strain gauges on the experimental model.

\subsection{Environmental Conditions}

Experiments under regular waves were conducted under three different wave heights (18 $\mathrm{mm}, 36 \mathrm{~mm}$, and $72 \mathrm{~mm}$ ) and wave periods from 0.7 to $4.1 \mathrm{~s}$. In higher wave cases, wave periods around natural periods of heave and pitch were mainly measured to discuss the effect of wave heights on the viscous damping.

\section{Numerical Methods}

\subsection{NK-UTWind Code Model}

First, the full-scale FOWT was numerically modeled and analyzed using a coupled analysis code for the rotor-floater-mooring response. The code used was the NK-UTWind (an in-house code developed by UTokyo for coupled analysis of FOWT, see [18]); other articles that present details about the use of NK-UTWind can be found, for example, in $[10,13,20]$.

The aerodynamic and inertia loads on the rotor part are integrated into the structure part. The structure is formulated with a finite element model and discretized into node elements and beam elements. Each node has three translational and three angular degrees of freedom. Thus, it can be formulated as given in Equation (1).

$$
[\mathrm{M}]\{\ddot{\mathrm{x}}\}+[\mathrm{C}]\{\dot{\mathrm{x}}\}+[\mathrm{K}]\{\mathrm{x}\}=\left\{\mathrm{F}^{\text {hydro }}+\mathrm{F}^{\text {lines }}+\mathrm{F}^{\text {buoyancy }}+\mathrm{F}^{\text {aero }}\right\}
$$

where $[\mathrm{M}]$ is the mass matrix whose dimension is $6 \mathrm{~N}$ for the structural model of $\mathrm{N}$ nodes, $[\mathrm{C}]$ the damping matrix, $[\mathrm{K}]$ the structural stiffness matrix, and $\mathbf{x}$ denotes the nodal displacement vector and its first derivative and second derivative denote the velocity and acceleration vectors, respectively. The right-hand side vector comprises four force components: the hydrodynamic force, the forces from mooring lines, the restoring force, and the aerodynamic force. The hydrodynamic force is evaluated based on Morison's Equation [21], 
as given in Equation (2). It can be applied for slender structures that are hydrodynamically transparent.

$$
\text { F hydro }=\rho \frac{\pi \mathrm{D}^{2}}{4} \dot{\mathrm{v}}+\mathrm{C}_{\mathrm{m}} \rho \frac{\pi \mathrm{D}^{2}}{4}(\dot{\mathrm{v}}-\ddot{\mathrm{x}})+\mathrm{C}_{\mathrm{D}} \frac{1}{2} \rho \mathrm{D}(\mathrm{v}-\dot{\mathrm{x}})|\mathrm{v}-\dot{\mathrm{x}}|
$$

where $\rho$ is the fluid density, $\mathrm{D}$ the diameter of the column element, and $\mathrm{v}$ the fluid particle velocity. Furthermore, $C_{m}$ and $C_{D}$ denote the added mass coefficient and drag force coefficient, respectively. The mooring force can be evaluated by either quasi-static catenary calculation, lumped-mass method, or linear spring. Wheeler's stretch method [22] was used to estimate wave forces for the submerged domain for each time step.

The mesh and nodes considered in the NK-UTWind code analysis are visualized in Figure 5. All the beam elements are modeled as circular cylinders. In this procedure, the sphere footings are approximated by three flat circular cylinders. The difference of footing geometries between the experiment and simplifications applied in the NKUTWind code can affect the added mass coefficient and drag force coefficient for each node considered in the numerical model. The added mass coefficients and drag coefficients for each simplified element were obtained from DNV-GL guidelines [23] as standard hydrodynamic coefficients for cylinders.

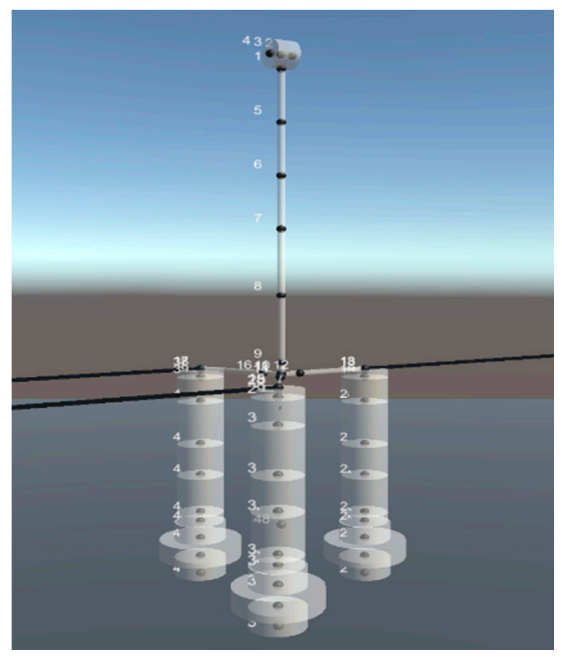

Figure 5. Mesh and nodes considered in the NK-UTWind code analysis.

In the NK-UTWind code, $6 \mathrm{DOF}$ motions were obtained for the motion of the center of gravity. The displacement of the tower top and column bottom was evaluated by the elastic deformation using bending moment on each beam.

\subsection{WAMIT Code Model}

The dynamic behavior of the FOWT was also evaluated by WAMIT code, a program based on the linear potential theory to analyze submerged or floating objects under waves. It does not consider the effect of viscosity and can be applied to rigid body motions. Furthermore, the WAMIT code evaluates the hydrodynamic loads in the frequency domain.

One of the purposes of using WAMIT is to confirm the motion responses as a rigid body. The other is to reveal the difference of the motion responses arisen by the different evaluation methods of the potential theory and Morison equation.

The WAMIT code simulation was performed with a low-order mesh composed of 558 flat quadrilateral and triangular panels with a mean edge of approximately $4.3 \mathrm{~m}$ in full scale, as illustrated in Figure 6a. The mooring line characteristics were included in the software Edtools ${ }^{\circledR}$ that calculated the full stiffness matrix using the formulation as 
presented in [24]. The non-diagonal terms due to the degree-of-freedom coupling were also considered. The 3D view of the Edtools ${ }^{\circledR}$ model is shown in Figure $6 \mathrm{~b}$.

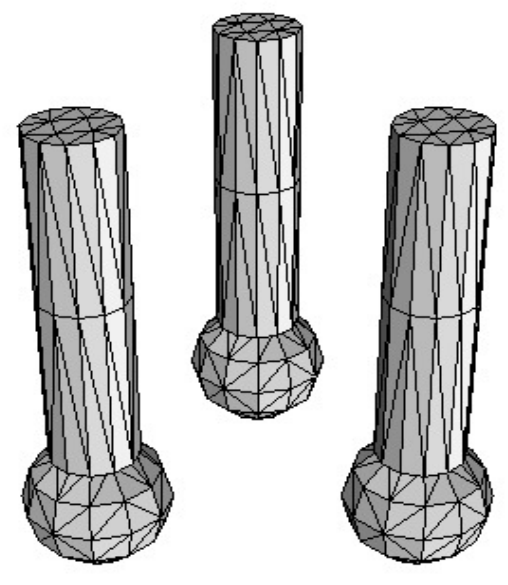

(a)

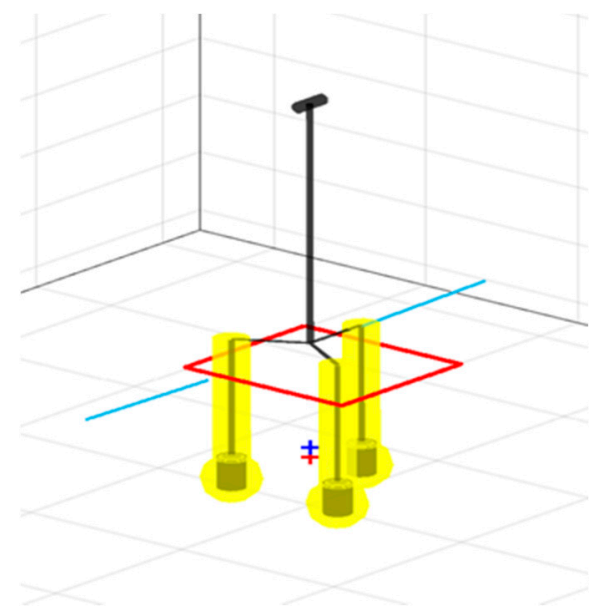

(b)

Figure 6. View of the WAMIT code models: (a) low order mesh considered in the WAMIT code analysis; (b) mooring setup in Edtools ${ }^{\circledR}$.

Since the viscous effect is not considered in the potential theory calculation, the viscous effect was incorporated into the external damping analysis. The external damping was estimated firstly from the free decay tests and incorporated into the numerical model.

\subsection{Ansys Model}

Modal analysis to reveal the elastic mode and vibrations of the structure was performed using the Ansys ${ }^{\circledR}$ code. The model geometry was built using CAD software Rhinoceros ${ }^{\circledR}$, and the position and dimensions of the model were obtained from Edtools ${ }^{\circledR}$. The main properties of the model are shown in Table 4 . The thickness of each structure was given to match the mass of each element.

Table 4. Main properties of the Ansys model as constructed in the model scale.

\begin{tabular}{ccccc}
\hline & $\begin{array}{c}\text { Mass } \\
{[\mathbf{k g}]}\end{array}$ & $\begin{array}{c}\text { Thickness } \\
{[\mathbf{m m}]}\end{array}$ & $\begin{array}{c}\text { E (Young's Modulus) } \\
{[\mathbf{P a}]}\end{array}$ & $\begin{array}{c}\text { Density } \\
{\left[\mathbf{k g} / \mathbf{m}^{3}\right]}\end{array}$ \\
\hline Nacelle & 0.32 & 0.85 & $1.93 \times 10^{13}$ & 7750 \\
Tower & 1.44 & 1.00 & $1.93 \times 10^{13}$ & 7750 \\
Deck & 0.29 & 1.50 & $1.93 \times 10^{13}$ & 7750 \\
Column & 0.59 & 1.00 & $1.93 \times 10^{13}$ & 7750 \\
Hull cylinder & 2.64 & 4.70 & $4.19 \times 10^{9}$ & 1050 \\
Hull Sphere & 1.87 & 5.30 & $4.19 \times 10^{9}$ & 1050 \\
Ballast & 30.19 & - & $2.00 \times 10^{11}$ & 7850 \\
\hline
\end{tabular}

The connection point between the structures that comprise the experimented FOWT must be correctly modeled in the Ansys ${ }^{\circledR}$ code to obtain the structure eigenmodes. Details about the connection points and Ansys ${ }^{\circledR}$ code model are presented in Figure 7. 


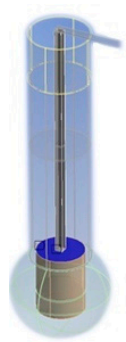

(a)

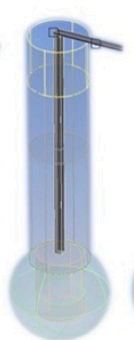

(b)

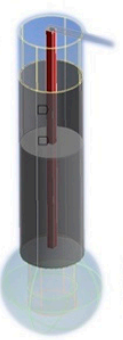

(c)

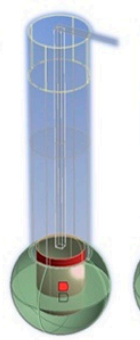

(d)

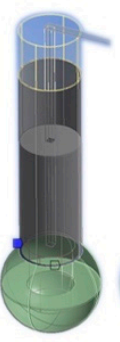

(e)

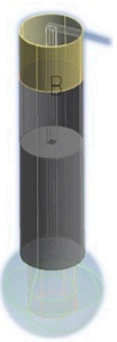

(f)

Figure 7. Connected points of the elements considered in the modal analysis by Ansys: (a) cylinder beam/ballast; (b) cylinder beam/deck; (c) cylinder beam/hull cylinder; (d) hull sphere/ballast; (e) hull cylinder/hull sphere; (f) hull cylinder/hull cylinder.

\section{Results and Discussions}

Three main results are discussed in herein: first, free decay and hammering tests; second, motion responses; and third, elastic displacements. All the results were obtained from experiments and numerical calculations (NK-UTWind and WAMIT codes). Numerical analyses were conducted in full-scale models; all the results were presented in the reduced scale $1 / 50$.

\subsection{Free Decay and Hammering Tests}

The results of the free decay test and hammering test are shown in Tables 5 and 6, respectively.

Table 5. Natural periods obtained from free decay tests.

\begin{tabular}{ccc}
\hline Degree of Freedom & Experiment [s] & NK-UTWind [s] \\
\hline surge & 31.30 & 31.90 \\
heave & 2.41 & 2.42 \\
pitch & 2.97 & 3.09 \\
\hline
\end{tabular}

Table 6. Most energetic vibration modes obtained from the hammering test.

\begin{tabular}{cccc}
\hline Degree of Freedom & Experiment [s] & NK-UTWind [s] & Ansys [s] \\
\hline $\begin{array}{c}\text { Gauge 2 } \\
\text { z-direction }\end{array}$ & 1.72 & 1.73 & 1.66 \\
\hline
\end{tabular}

The hammering test was performed with the model in the water in its initial position for wave tests. The same condition was simulated using the NK-UTWind code. The time series of bending along the $\mathrm{z}$-axis in the Gauge 2 position was compared. The natural period of the most energetic vibration mode at Gauge 2 along the Z-axis was around $1.7 \mathrm{~s}$ and showed a good match with differences of less than $1 \%$ between experiments and numerical calculations.

The differences in natural periods in the surge, heave, and pitch between NK-UTWind and the experiment were less than $4 \%$.

Ansys code simulations were performed in water to determine the eigenmodes of the FOWT. As a result of the simulations, three different resonant modes around $1.66 \mathrm{~s}$ were obtained. The first resonant mode of $1.66 \mathrm{~s}$ is shown in Figure 8. In the first eigenmode, it is possible to verify that all the bottom column displacements are in the same phase, and the displacements are aligned with the respective base deck line of each column. The eigenmode period was very similar to the ones obtained in the experiments and NK-UTWind code; therefore, this value can be considered validated. 


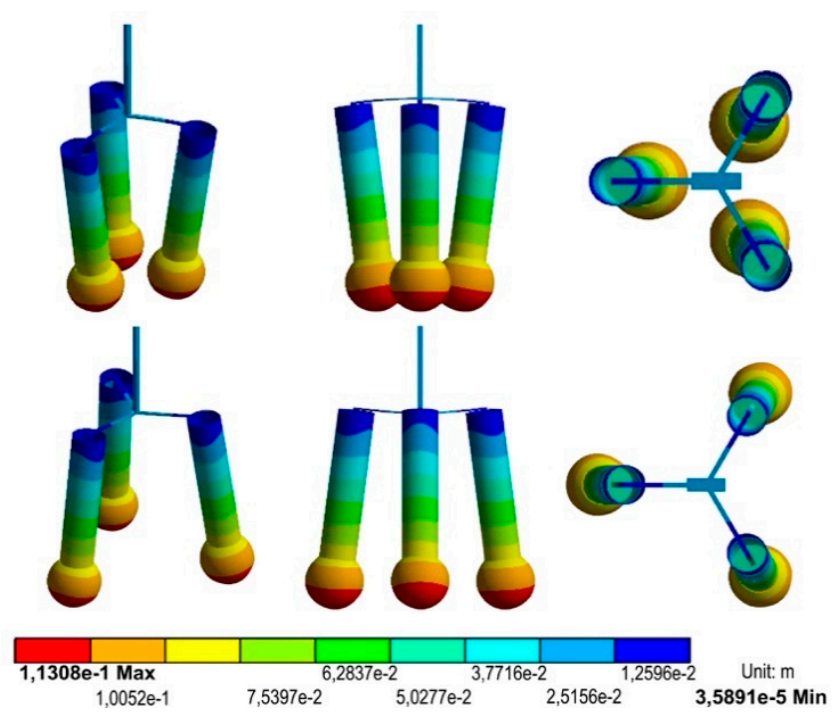

Figure 8. The first resonant mode obtained by Ansys code eigenmode analysis.

\subsection{Regular Wave Tests}

This section presents response amplitude operator (RAO) motions for heave and pitch and RAO motions for displacements at the tower top and column bottom. The RAOs were calculated under regular wave tests. Two main factors were analyzed to verify their effects on the dynamic behavior in regular waves of FOWT: first, the influence of the wave height; and second, the structural rigidity of the floater.

Concerning the terminology and symbols adopted, $\xi_{\mathrm{a}}$ is the wave amplitude, $\mathrm{k}$ is the wavenumber, and $\mathrm{k} \xi_{\mathrm{a}}$ is the maximum wave slope. $\xi_{33}$ and $\xi_{55}$ is the amplitude of heave and pitch motion, respectively. RAO results are presented in non-dimensional forms.

\subsubsection{Influence of the Wave Height}

Figures 9 and 10 present the comparison of RAO results between experiments and NK-UTWind calculations for heave and pitch motions, respectively. Three different wave heights were evaluated as $\mathrm{H}_{\mathrm{r}}=18,36$, and $72 \mathrm{~mm}$.

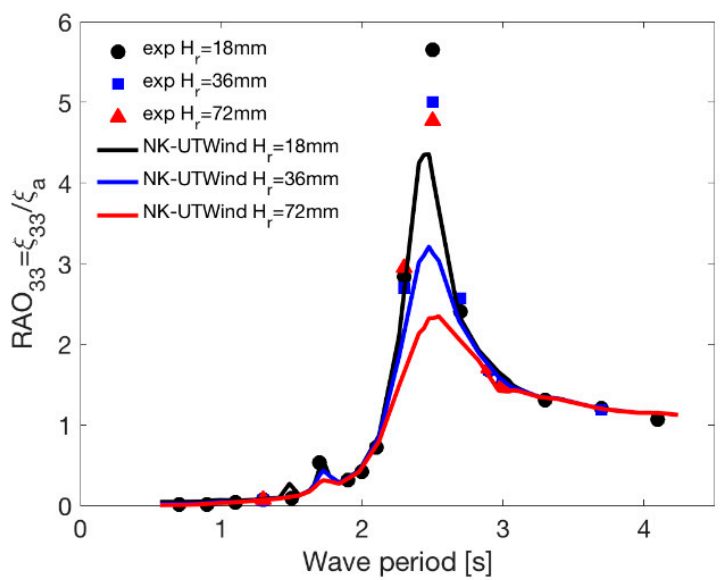

Figure 9. Response amplitude operator (RAO) heave motion result comparisons between the experiment and NK-UTWind numerical calculations for different wave heights. 


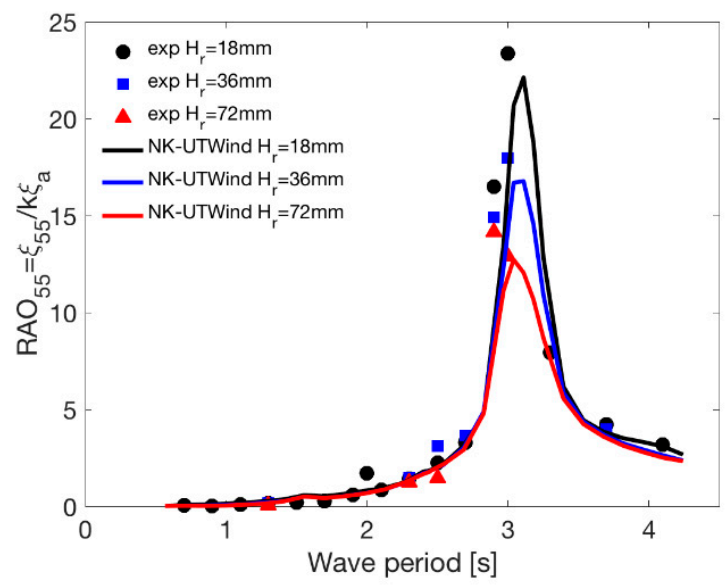

Figure 10. RAO Pitch motion result comparisons between the experiment and NK-UTWind numerical calculations for different wave heights.

In general, it is possible to observe a decrease in the peak value of the RAO around the natural periods when increasing the wave height. This fact was related to high damping values for high wave heights, which confirmed the pronounced quadratic (non-linear) behavior of the viscous damping.

Numerical results from the NK-UTWind code agreed very well with the experiments outside the resonance region. In the resonance region, the RAO values are very sensitive to the damping levels. The results showed that the damping level from NK-UTWind, provided mainly by the drag coefficients in the Morison equations, were higher than in the experiments. The discretization in nodes, i.e., slices of circular cylinders, of the footing region could provide more damping than the experimented case, therefore decreasing the peak value of the RAO results.

Figure 9 allows observing a small peak around the wave period equal to $1.70 \mathrm{~s} .1 .72 \mathrm{~s}$ represent the natural period of the most energetic vibration mode obtained from the hammering tests; see Figure 6. The eigenmode elastic behavior was remarkable, and it was visible during the experiments due to the significant displacements of the column bottoms.

Figure 10 permits to conclude that the peak value of the RAO pitch results showed a relatively better agreement between the experiment and numerical simulation than the heave one. The reason was that the difference in the damping levels due to the footing geometry modeling affected the pitch motion less. The drag coefficient in the x-axis direction is responsible for the main viscous damping coefficient; therefore, the drag coefficient approximation from DNV for a cylinder in the x-axis direction was better than the one for the $\mathrm{z}$-axis direction.

Figure 11 shows the behavior occurred in the experiments that almost corresponded with the resonant mode shown in Figure 9.
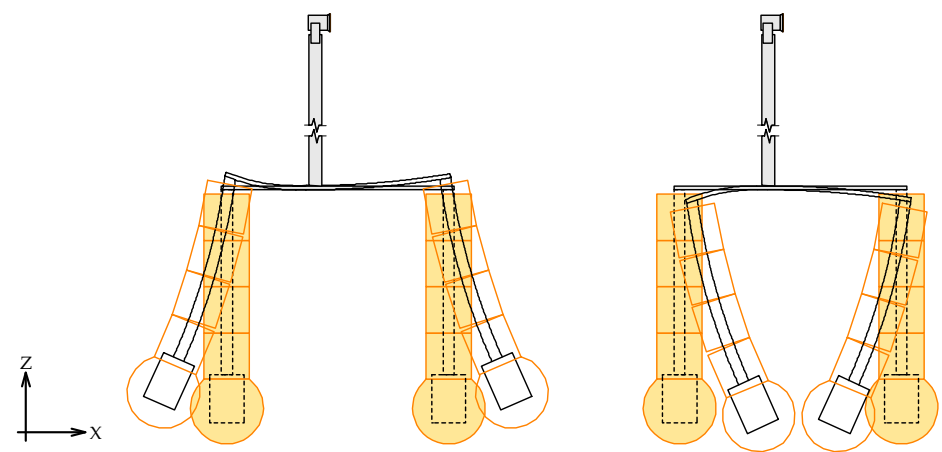

Figure 11. Schematic of the response mode for the $1.7 \mathrm{~s}$ wave period. 
Figures 12 and 13 present the comparison of RAO results between experiments and WAMIT code calculations for the heave and pitch motions, respectively. Four different external damping values (viscous damping) were evaluated to show how sensitive the $\mathrm{RAO}$ is to this parameter. Zero damping condition and three different external damping levels were selected to match the peak value of the experimental RAOs.

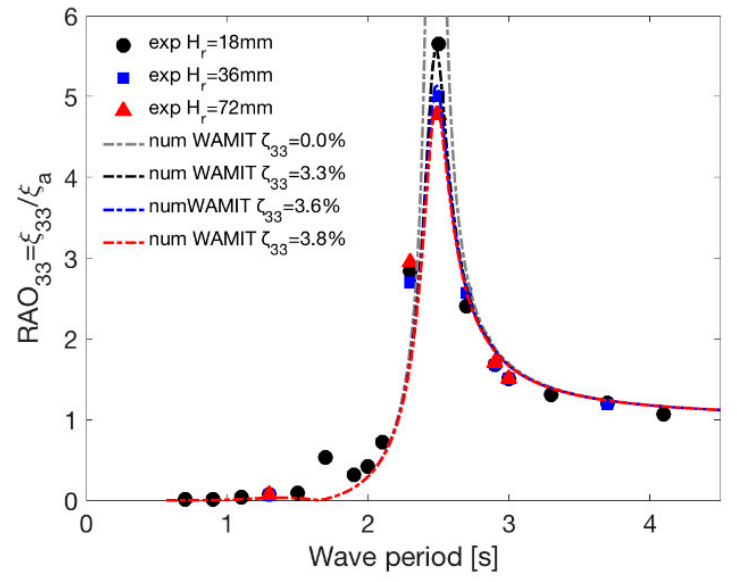

Figure 12. RAO heave motion result comparisons between the experiment and WAMIT numerical calculations for different external damping levels.

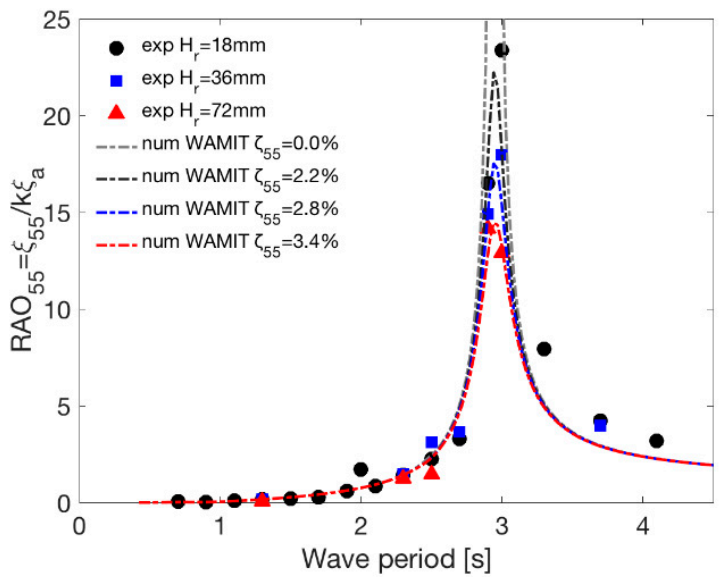

Figure 13. RAO pitch motion result comparisons between the experiment and WAMIT numerical calculations for different external damping levels.

The linear potential theory cannot calculate the non-linear effects on RAOs due to the wave height. Since we know that the most significant part of this effect is due to the quadratic nature of the viscous damping, different levels of external damping can be included in the WAMIT simulations to simulate the wave high effect. The system total damping comprises potential damping and external (viscous damping, mooring lines, and other sources). The potential damping was neglected as the WAMIT calculations showed low values; the external damping due to the mooring line and other external sources was also considered small for the DOF of interest; thus, most external damping came from the viscous forces.

In general, the numerical RAOs calculated from the WAMIT code showed a good agreement with the experiments using the corrected calibrated damping level. It means that the peak values of RAOs presented the same values in the numerical calculations and experiments. The damping ratio, $\zeta$, was calculated in terms of the percentage of critical damping for the respective DOF. An increase of four times the wave height was responsible for modifying around $0.5 \%$ and $1.2 \%$ the damping ratio levels for heave and pitch. 
The numerical results from the WAMIT code were calculated for a rigid body; due to that, the RAO heave peak around $1.7 \mathrm{~s}$, which represented the energy around the natural period of the flexible mode, did not reproduce the experimental results, as seen in Figure 12.

\subsubsection{Influence of the Structural Rigidity}

Punctual displacements due to the elastic deformation of the tower top, column bottom, and deck edge are induced mainly by bending moments when excluding the rigid-body motions of the floater. For the punctual displacement of the column bottom, the deck deformation was summed with the column deformation itself. Figure 14 represents the definition of the punctual deformations due to the elastic behavior of the tower, deck, and column.

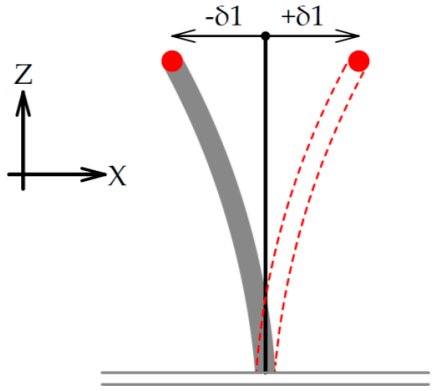

(a)

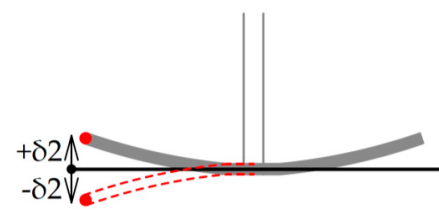

(b)

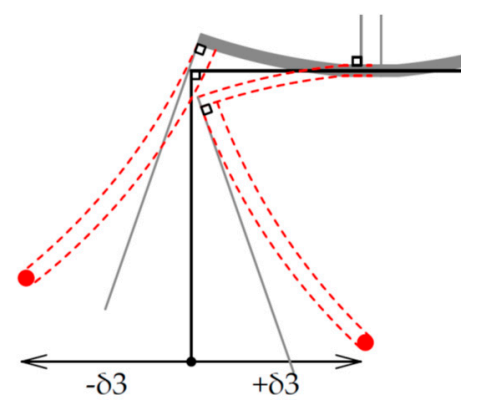

(c)

Figure 14. Definition of punctual displacements due to the elastic deformation for each element: (a) tower top displacement due to the elastic deformation $(\delta 1) ;(\mathbf{b})$ deck edge elastic displacement due to the elastic deformation ( $\delta 2)$; (c) column bottom displacement due to the elastic deformation displacement ( 83$)$.

The procedure to estimate the punctual displacement from the bending moment due to the elastic deformation is explained below. It was fundamentally based on the EulerBernoulli Hypothesis, i.e., cross-sections vertical to neutral plane remain vertical even after deformed.

For the tower top displacement, the linear relationship described as Equation (3) was assumed between the bending moment, $\mathrm{M}_{1}$, and the distance from the tower top $\mathrm{x}_{1}$. The constant of proportionality is defined as $\mathrm{P}_{1}$, considered the concentrated force at the tower top.

$$
\mathrm{M}_{1}=\mathrm{P}_{1} \mathrm{x}_{1}
$$

After this assumption, the tower is regarded as the cantilever stuck at the deck base, and $\delta 1$ is calculated as Equation (4), where tower length is $L_{1}$, and the flexural rigidity of the tower is $\mathrm{EI}_{1}$.

$$
\delta 1=\frac{\mathrm{P}_{1} \mathrm{~L}_{1}{ }^{3}}{3 \mathrm{EI}_{1}}
$$

For the deck edge, the bending moment is measured at only one point as $\mathrm{M}_{2}$ and assumed to be subject to uniformly distributed load. Then $\delta 2$ can be calculated as Equation (5), where the deck length is $\mathrm{L}_{2}$, and the flexural rigidity of the deck is $\mathrm{EI}_{2}$.

$$
\delta 2=\frac{\mathrm{M}_{2} \mathrm{~L}_{2}{ }^{2}}{2 \mathrm{EI}_{2}}
$$

For the column bottom, the linear relationship described as Equation (6) was assumed between bending moment, $\mathrm{M}_{3}$, and the distance from the column bottom $\mathrm{x}_{3}$. The constant of proportionality is defined as $\mathrm{P}_{3}$, considered the concentrated force at the column top

$$
\mathrm{M}_{3}=\mathrm{P}_{3} \mathrm{x}_{3}
$$


After this assumption, the deck and column are regarded as L-shaped beams, and $\delta 3$ is calculated as Equation (7). The Equation represents the sum of displacement by deck tip angle and the deflection of the column itself, whereby the column length is $\mathrm{L}_{3}$, and the flexural rigidity of the column is $\mathrm{EI}_{3}$.

$$
\delta 3=\frac{\mathrm{M}_{2} \mathrm{~L}_{2}}{\mathrm{EI}_{2}} \mathrm{~L}_{3}+\frac{\mathrm{P}_{3} \mathrm{~L}_{3}{ }^{3}}{3 \mathrm{EI}_{3}}
$$

One of the current research goals is to investigate the effects of the model flexibility on the dynamic behavior in waves. A comparison of numerical models with different rigidity is a feasible alternative since the NK-UTWind was validated against the experimental results and evaluated these effects on the response of a FOWT in waves.

Based on the definitions proposed in Figure 14, punctual displacements due to the elastic deformation of the tower top, deck edge, and column bottom were obtained using the NK-UTWind code. Numerical models with three different rigidities, namely $0.7 \mathrm{EI}_{0}, \mathrm{EI}_{0}$, and $5 \mathrm{EI}_{0}$ were simulated; where, $\mathrm{EI}_{0}$ is the original rigidity of the experimental model. The simulations were performed for a wave height of $18 \mathrm{~mm}$ in the model scale.

The displacement results were presented as RAOs in a non-dimensional form in Figures 15-17, respectively, for three points located at the tower top, deck edge, and column bottom. For experimental results, the bending moment values were obtained from strain gage measurements as detached in Figure 4. The same procedure was applied for the NK-UTWind results, in which numerical measurements were obtained in the same position as the experimented gages. Figure 17 shows that the bottom columns indirect displacements were evaluated using the column top as a rigid body and measured by the Qualysis ${ }^{\circledR}$ system to confirm the gauge measurements. In this case, the second term in Equation (7) is zero, and only the effect of the bending angle of a deck tip is considered.

In general, the punctual results for the most rigid model, $5 \mathrm{EI}_{0}$, were much lower compared to the two other cases, as expected. Some punctual displacements were observed because the model was not sufficiently rigid to avoid them. The most flexible case presented the largest punctual displacements.

In Figure 15, the punctual displacement of the tower top was the largest at the natural period of the pitch, and NK-UTWind overpredicted it compared with experiments.

The results in Figures 16 and 17 resembled each other because the deflection of the bottom column itself was much smaller than the effective displacement by the deck edge angle.

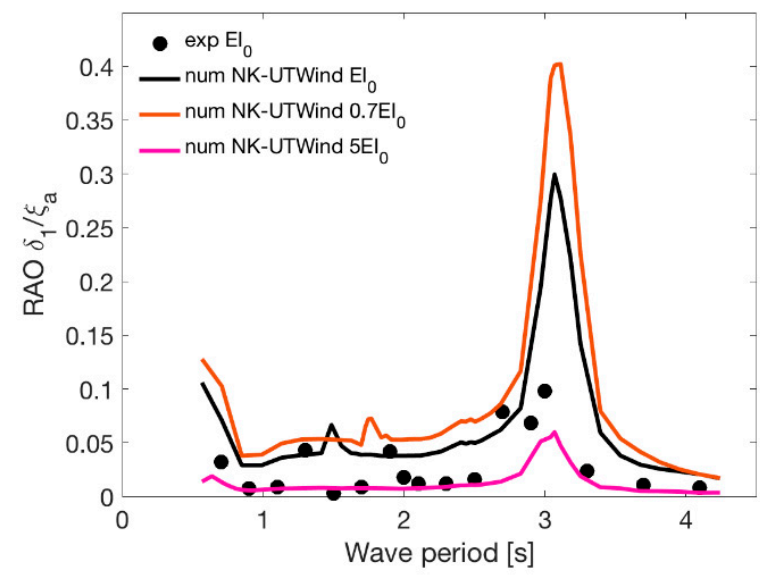

Figure 15. RAO punctual displacement due to the elastic deformation at the tower top result comparisons between the experiment and NK-UTWind numerical calculation for different structural rigidities. 


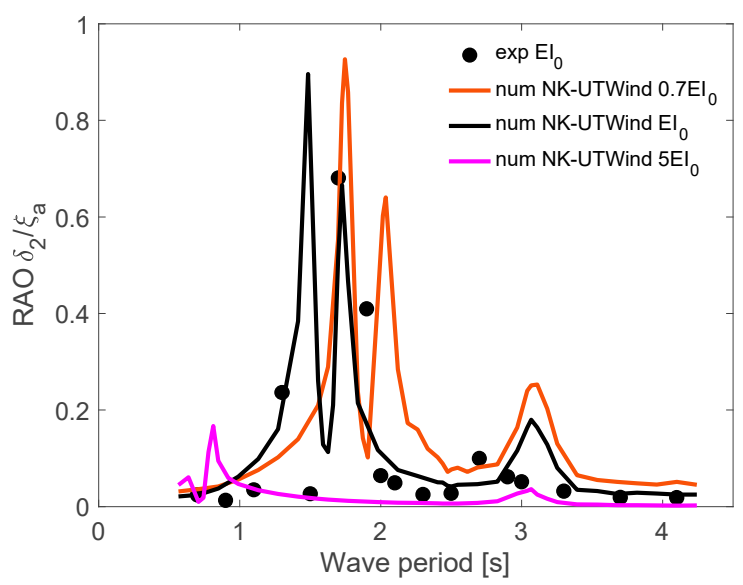

Figure 16. RAO punctual displacement due to the elastic deformation at the deck edge result comparisons between the experiment and NK-UTWind numerical calculation for different structural rigidities.

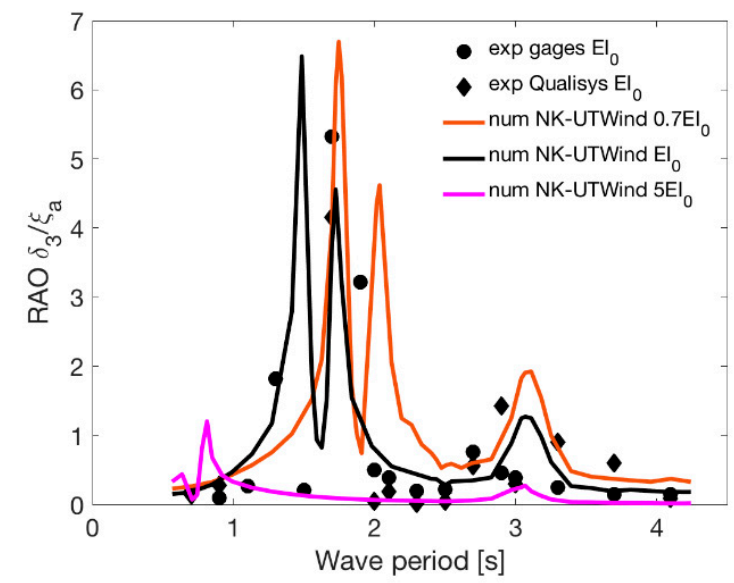

Figure 17. RAO punctual displacement due to the elastic deformation at the column bottom result comparisons between the experiment and NK-UTWind numerical calculation for different structural rigidities.

From the experiment, a peak around a wave period of $1.7 \mathrm{~s}$ was observed; from the NK-UTWind numerical calculations, the presence of two large peaks around $1.7 \mathrm{~s}$, and a small peak around the natural period of the pitch.

For the $\mathrm{EI}_{0}$ case, the peak around $1.7 \mathrm{~s}$ could be explained by the experimental and NK-UTWind hammering test results and confirmed by eigenmode analysis using the Ansys code, i.e., the peak was due to the excitation of the natural period of the most energetic vibration mode. In turn, the $1.5 \mathrm{~s}$ peak could not be found in the experimental results in waves or the hammering test results. This difference between the experimental results and NK-UTWind simulations can be attributed to the difference in modeling the joint between decks and columns. Furthermore, the structural damping that can occur in the real structure could not be included in the NK-UTWind formulations. Due to the lower rigidity, the eigenmode on $1.7 \mathrm{~s}$ for $\mathrm{EI}_{0}$ moved to $2.1 \mathrm{~s}$ for $0.7 \mathrm{EI}_{0}$.

The previous results showed that the floater structural elastic behavior was presented in the experiments in waves, and it was represented in the numerical calculations using NK-UTWind. The same models were utilized to verify the structural elastic behavior effect on the dynamic response in waves through RAO analysis.

Figures 18 and 19 present the comparison of RAO results between experiments and NK-UTWind calculations for heave and pitch motions, respectively, for different structural rigidities. Three different structural rigidities were evaluated as $0.7 \mathrm{EI}_{0}, \mathrm{EI}_{0}$, and $5 \mathrm{EI}_{0}$. 


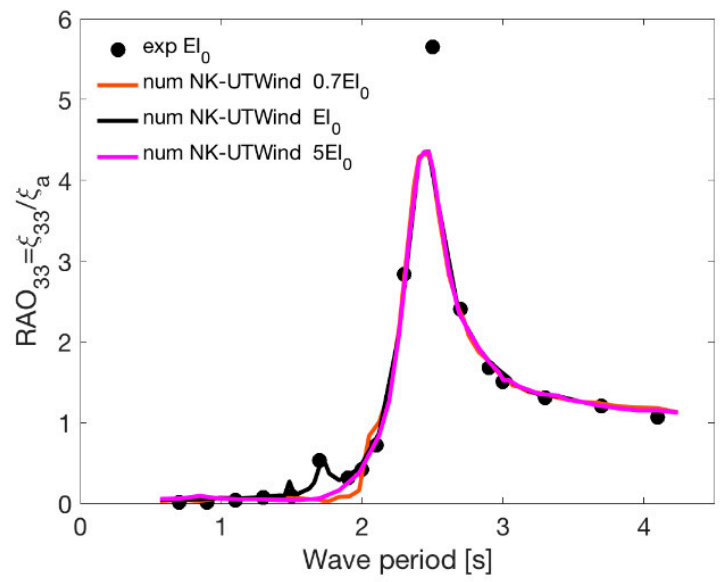

Figure 18. RAO heave motion result comparisons between the experiment and NK-UTWind numerical calculations for different structural rigidities.

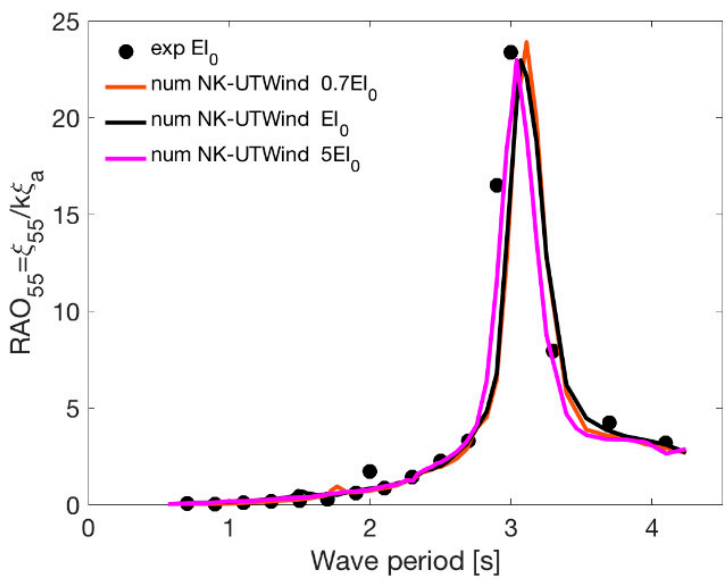

Figure 19. RAO pitch motion result comparisons between the experiment and NK-UTWind numerical calculations for different structural rigidities.

For the RAO heave, in Figure 18, small peaks could be seen for $\mathrm{EI}_{0}$ around the wave period of $1.5 \mathrm{~s}$ and $1.7 \mathrm{~s}$. For the $0.7 \mathrm{EI}_{0}$ model, there is a sharp inclination around the wave period of $2.0 \mathrm{~s}$. The explanation for these peaks was the presence of the structural vibration mode, as discussed for the punctual displacements of the deck edge and column bottom. Outside the aforementioned wave periods, the effect of the structural elastic behavior could be neglected. However, the structural elastic behavior impact must not be ignored when studying FOWTs. The typical sea states have high energy levels before $2 \mathrm{~s}$ (in the model scale 1/50) and $14 \mathrm{~s}$ (in the full scale). High response levels before $2 \mathrm{~s}$ can directly impact the fatigue of mooring lines and decrease these systems lives and increase the operating costs.

For the RAO pitch, in Figure 19, no significant differences were observed for different structural rigidities.

Although there were small peaks due to the consideration of the structural elastic behavior on the RAO heave, as seen in Figure 18, it may not be negligible in designing a FOWT model. Spectral analysis of the heave motion may result in significant amplitudes under an actual ocean environment. A discussion can be held to verify the structural vibration influence on the heave motion statistics under a real operational sea environment. For example, an operational sea condition characterized by significant wave height, $\mathrm{H}_{\mathrm{s}}=2.5 \mathrm{~m}$, and mean wave period, $\overline{\mathrm{T}}=1 / \overline{\mathrm{f}}=9.0 \mathrm{~s}\left(\right.$ or $\mathrm{T}_{\mathrm{p}}=1.27 \mathrm{~s}$ ), was utilized (values in full scale). The heave response spectrum for the models with two different rigidities, 
$\mathrm{EI}_{0}$ and $5 \mathrm{EI}_{0}$, were performed. For the wave spectrum, the ISSC spectrum, see [25], was considered as:

$$
\mathrm{S}_{\mathrm{W}}(\mathrm{f})=\frac{\mathrm{A}}{\mathrm{f}^{5}} \exp \left(-\frac{\mathrm{B}}{\mathrm{f}^{4}}\right)
$$

where $\mathrm{A}=0.1107 \mathrm{H}_{\mathrm{s}}{ }^{2} \overline{\mathrm{f}}^{4}, \mathrm{~B}=0.4427 \overline{\mathrm{f}}, \overline{\mathrm{f}}=1.25 \mathrm{f}_{\mathrm{p}}$, and $\mathrm{f}_{\mathrm{p}}$ is the peak frequency of the wave spectrum. The wave spectrum in the model scale is shown in Figure 20.

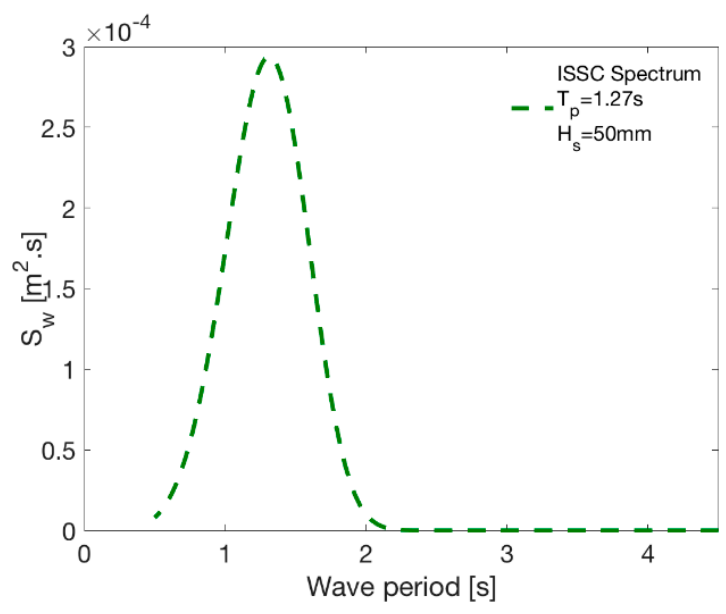

Figure 20. Power spectrum for an operational sea state $H_{s}=50 \mathrm{~mm}$ and $T_{p}=1.27 \mathrm{~s}$ in model scale.

For the $\mathrm{EI}_{0}$ model, the peak period of the wave spectrum was close to the natural frequency of the structural mode of vibration, which can magnify the heave response spectrum. The power spectrum of the heave motion response presented in Figure 21, $S_{33}(f)$, was calculated as:

$$
\mathrm{S}_{33}(\mathrm{f})=\left|\mathrm{RAO}_{33}(\mathrm{f})\right|^{2} \mathrm{~S}_{\mathrm{w}}(\mathrm{f})
$$

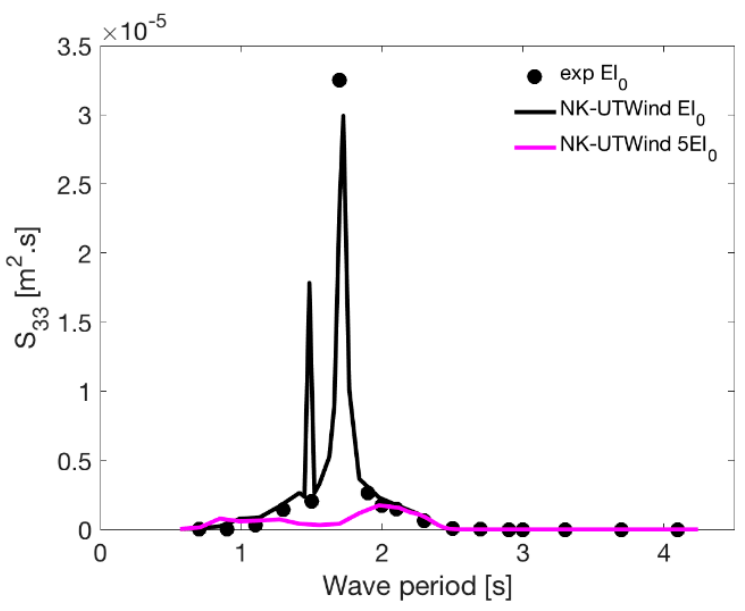

Figure 21. Power spectrum of heave motion response due to the operational sea state condition.

The variance of the heave motion in these wave conditions was estimated from the 0 th moment $\mathrm{m}_{0}$ of the heave response spectrum as:

$$
\mathrm{m}_{0}=\int \mathrm{S}_{33}(\mathrm{f}) \mathrm{df}
$$

The significant response of heave is evaluated as $4 \sqrt{\mathrm{m}_{0}}$. The results of significant wave height were 24.2 and $13.4 \mathrm{~mm}$ for the $\mathrm{EI}_{0}$ and $5 \mathrm{EI}_{0}$ models. The statistical results showed that the considerable heave response for the flexible model $\mathrm{EI}_{0}$ was $80 \%$ larger than the 
rigid model $5 \mathrm{EI}_{0}$. The massive difference of 1.8 times for this specific model and operational sea condition suggested that floater structural elastic behavior must be considered when designing light FOWT structures. Thus, the rigidity effects on the dynamic behavior in waves are essential.

\subsection{Comparison of Numerical Results from NK-UTWind and WAMIT}

The NK-UTWind and WAMIT codes employ different methods for evaluating wave forces. This difference can appear when comparing the results from the NK-UTWind code for a rigid model under low wave height with the ones from the WAMIT code and applying the external damping level to calibrate the RAO peak values.

Figures 22 and 23 present the comparison of RAO results between NK-UTWind and WAMIT numerical calculations for heave and pitch motions, respectively. The NK-UTWind model was calculated for wave height equal to $0.2 \mathrm{~m}$ (in the full scale) and the most rigid structural value $5 \mathrm{EI}_{0}$. The WAMIT model was evaluated for damping ratios of $\zeta_{33}=1.5 \%$ and $\zeta_{55}=1.7 \%$, heave and pitch, respectively.

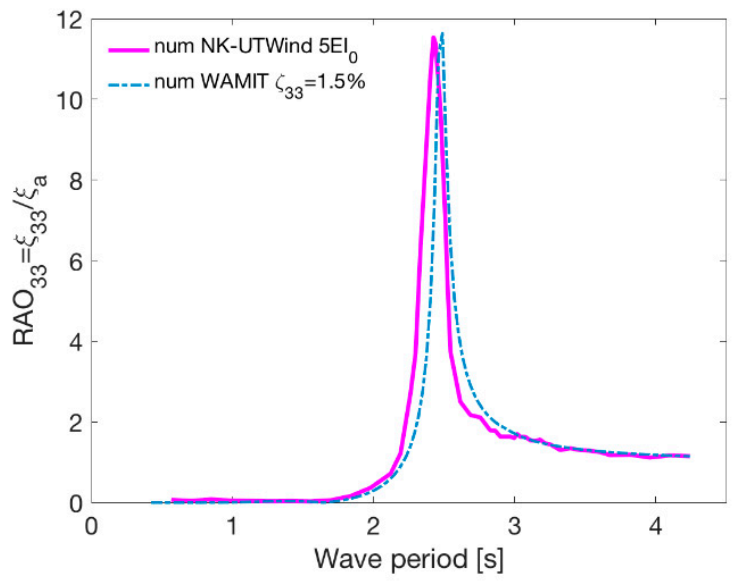

Figure 22. RAO heave motion result comparisons between the NK-UTWind and WAMIT numerical calculations.

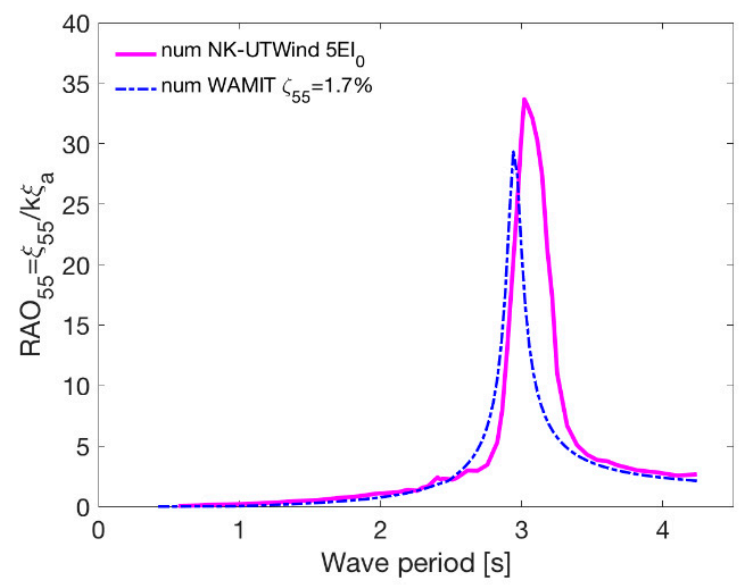

Figure 23. RAO pitch motion result comparisons between the NK-UTWind and WAMIT numerical calculations.

For the RAO heave, the NK-UTWind and WAMIT codes presented an excellent agreement, including peak values and natural period, as shown in Figure 22.

For the RAO pitch, the NK-UTWind and WAMIT codes presented a good agreement for wave periods shorter than $2.5 \mathrm{~s}$. A small difference was observed for the value of the natural period of the pitch, as shown in Figure 23. The difference may be the added mass 
calculations in the NK-UTWind code; as highlighted before, the footing geometry was simulated as three circular cylinders that impacted the added mass and, consequently, in the natural period of the pitch. The discrepancy was more pronounced for pitch motions than for heave ones due to the distance between the footing and the center of gravity, which impacted a more considerable added mass difference when considering the momentum arm.

\section{Conclusions}

In this research, a water tank experiment was carried out under regular waves using a flexible multi-column FOWT model. Dynamic motions and deformations of the model were featured and compared with NK-UTWind and WAMIT codes numerical calculations.

In the experiment, significant elastic deformation of the model was observed around the wave period of $1.7 \mathrm{~s}$. The comparison between RAO heave from the experiment, NKUTWind, and WAMIT simulations revealed that this elastic behavior affected the heave motion of the model. A small peak appeared in the RAO heave around the wave period of $1.7 \mathrm{~s}$, and the same peak was observed in the experiment and NK-UTWind simulation, but not in the WAMIT simulation. However, except for the natural period of the structural vibration, the motion as a rigid body was dominant for the motion responses. Indeed, the WAMIT simulation has reasonable estimations of the RAOs of the experiment except for the wave period of $1.7 \mathrm{~s}$.

Although the experimental results rarely estimate the displacements deriving from the elastic deformation, this work figured them out from strain gages applying some assumptions. The displacements from strain gages were compared with those calculated by the NK-UTWind code. The NK-UTWind calculation showed a larger displacement of deck edges and column bottoms under a wave period of $1.7 \mathrm{~s}$ than the experimental results. In turn, the displacement of the tower top was over-estimated numerically.

In investigating the structural rigidity effect on the motion response, it was possible to observe a small peak in RAO heave affected by elastic vibration compared with the rigid model. The slight difference seemed negligible compared to the peak values around the natural period; however, the spectral results under a real ocean environment greatly impacted the significant heave height results. The significant heave height was $80 \%$ higher for the flexible model than the rigid one when using an operational sea state condition. The need to consider the rigidity effects on the dynamic behavior of a light FOWT was brought about.

NK-UTWind and WAMIT calculations showed good agreements when considering rigid models under low wave heights; no significant differences could be found in the RAO heave. Simultaneously, for the RAO pitch, a small difference in the natural period was recognized. The difference was due to the evaluation method of hydrodynamic forces, specifically the added mass.

As a summary of NK-UTWind and WAMIT codes, they showed to be useful tools for the preliminary design of FOWT. NK-UTWind code can well represent the non-linearities due to the wave height and include the floater structural elastic behavior. The WAMIT code can be useful to calculate the added mass coefficients and to calibrate the damping levels. Using both tools together, it is possible to obtain more reliable results than using them separately. In another way, NK-UTWind with potential theory can be expected for better estimating of dynamic behaviors.

Author Contributions: Conceptualization, H.S., K.I., S.O. and K.H.; methodology, H.S., K.I., Y.Y., H.H., R.T.G. and M.T.; software, R.T.G., E.B.M., R.D. and T.T.; validation, H.S. and H.H.; formal analysis, R.T.G., E.B.M., R.D., M.T., K.H. and T.T.; investigation, H.H., R.T.G., M.T., K.H. and T.T.; resources, Y.Y. and K.I.; data curation, H.H., M.T., K.H. and T.T.; writing-original draft preparation, R.T.G. and T.T.; writing-review and editing, R.T.G., H.H. and T.T.; supervision, H.S., K.I., H.H. and R.T.G.; project administration, Y.Y. and M.T.; funding acquisition, H.S., K.I. and M.T. All authors have read and agreed to the published version of the manuscript. 
Funding: This research is based on the results obtained from a project supported by New Energy and Industrial Technology Development Organization (NEDO), Japan.

Institutional Review Board Statement: Not applicable.

Informed Consent Statement: Not applicable.

Data Availability Statement: No new data were created or analyzed in this study. Data sharing is not applicable to this article.

Acknowledgments: The authors would like to thank Eng. Sakamoto, H. from Fractaly Co. Ltd., Japan, for model manufacturing and assembly, and Kato, T. the technical staff of the towing tank of UTokyo, for his technical support in conducting the experiments. The authors also would like to thank the student Marques, M. A. from the Federal University of Pernambuco (UFPE), Brazil, for his help during the image developments.

Conflicts of Interest: The authors declare no conflict of interest.

\section{Abbreviations}

B center of floatation

BM metacentric radius [m]

$[C] \quad$ damping matrix

$C_{D} \quad$ drag force coefficient

$C_{m} \quad$ added mass coefficient

$D \quad$ diameter of column element [m]

E elastic modulus [Pa]

EI flexural rigidity [N.m²]

$E I_{0} \quad$ flexural rigidity of the experimental model as a whole [N.m $\left.{ }^{2}\right]$

$E I_{1} \quad$ flexural rigidity of the tower $\left[\mathrm{N} . \mathrm{m}^{2}\right]$

$E I_{2} \quad$ flexural rigidity of the deck [N.m $\left.{ }^{2}\right]$

$\mathrm{EI}_{3} \quad$ flexural rigidity of the column $\left[\mathrm{N} . \mathrm{m}^{2}\right]$

$f \quad$ wave frequency $[\mathrm{Hz}]$

$F^{\text {aero }} \quad$ aerodynamic force $[\mathrm{N}]$

$F^{\text {buoyancy }}$ restoring force [N]

Fhydro hydrodynamic force [N]

Flines mooring forces $[\mathrm{N}]$

$f_{p} \quad$ peak frequency of the wave spectrum $[\mathrm{Hz}]$

$\bar{f} \quad$ mean wave frequency $[\mathrm{Hz}]$

$G \quad$ center of gravity

GM metacentric height [m]

$H_{r} \quad$ regular wave height [m]

$H_{S} \quad$ significant wave height $[\mathrm{m}]$

I moment of inertia of area $\left[\mathrm{m}^{4}\right]$

$[K] \quad$ structural stiffness matrix

$K \quad$ keel point

$k \quad$ wave number $[1 / \mathrm{m}]$

$k_{s} \quad$ spring constant $[\mathrm{N} / \mathrm{m}]$

$K B \quad$ distance from the buoyance center to the keel point [m]

$K G \quad$ distance from the center of gravity to the keel point [m]

$l_{0} \quad$ initial tension $[\mathrm{N}]$

$L_{1} \quad$ tower length [m]

$L_{2} \quad$ deck length [m]

$L_{3} \quad$ column length [m]

[M] mass matrix

M metacenter

$M_{1} \quad$ bending moment at tower [N.m]

$M_{2} \quad$ bending moment at deck [N.m]

$M_{3} \quad$ bending moment at column [N.m]

$P_{1} \quad$ concentrated force at the tower top [N] 


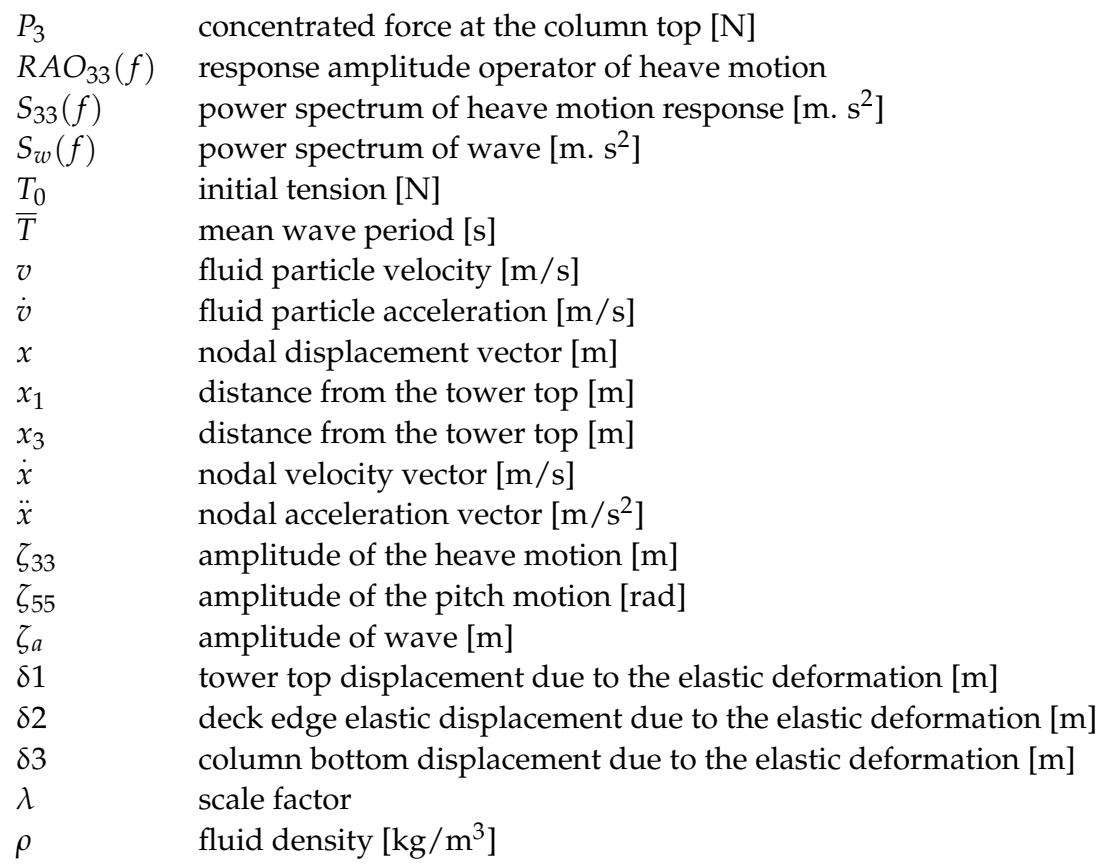

\section{References}

1. Goupee, A.J.; Koo, B.J.; Kimball, R.W.; Lambrakos, K.F.; Dagher, H.J. Experimental comparison of three floating wind turbine concepts. J. Offshore Mech. Arctic Eng. 2014, 126, 1-9. [CrossRef]

2. Jonkman, J.M. Dynamics Modeling and Loads Analysis of an Offshore Floating Wind Turbine; Technical Report; NREL/TP-500-41958; National Renewable Energy Lab.: Golden, CO, USA, 2007.

3. Sakamoto, N.; Yoshimura, Y. Demonstration research on NEDO offshore wind condition observation system and offshore wind power generation system offshore Kitakyushu City. Wind Energy 2013, 37, 151-155. (In Japanese)

4. Borisade, F.; Choisnet, T.; Cheng, P.W. Design study and full scale MBS-CFD simulation of the IDEOL floating offshore wind turbine foundation. J. Phys. Conf. Ser. 2016, 753, 092002. [CrossRef]

5. Beyer, F.; Choisnet, T.; Kretschmer, M.; Cheng, P.W. Coupled MBS-CFD simulation of the IDEOL floating offshore wind turbine foundation compared to wave tank model test data. In Proceedings of the 25th International Ocean and Polar Engineering Conference (ISOPE), Kona, HI, USA, 21-26 June 2015.

6. Kosasih, K.M.A.; Suzuki, H.; Niizato, H.; Okubo, S. Demonstration experiment and numerical simulation analysis of full-scale barge-type floating offshore wind turbine. J. Mar. Sci. Eng. 2020, 8, 880. [CrossRef]

7. Pan, J.; Ishihara, T. Numerical prediction of hydrodynamic coefficients for a semi-submersible platform by using large eddy simulation with volume of fluid method and Richardson extrapolation. J. Phys. Conf. Ser. 2019, 1356, 012034. [CrossRef]

8. Ishihara, T.; Zhang, S. Prediction of dynamic response of semi-submersible floating offshore wind turbine using augmented Morison's Equation with frequency dependent hydrodynamic coefficients. Renew. Energy 2019, 131, 1186-1207. [CrossRef]

9. Ohta, M.; Komatsu, M.; Ito, H.; Kumamoto, H. Development of a V-shaped semi-submersible floating structure for 7MW offshore turbine. In Proceedings of the World NAOE Forum 2013 \& International Symposium on Marine and Offshore Renewable Energy, Tokyo, Japan, 28-30 October 2013.

10. Suzuki, H.; Shiohara, H.; Schnepf, A.; Houtani, H.; Carmo, L.H.S.; Hirabayashi, S.; Haneda, K.; Chujo, T.; Nihei, Y.; Malta, E.B.; et al. Wave and wind responses of a very-light FOWT with guy-wired-supported tower: Numerical and experimental studies. J. Mar. Sci. Eng. 2020, 8, 841. [CrossRef]

11. Yoshimoto, H.; Natsume, T.; Sugino, J.; Kakuya, H.; Harries, R.; Alexandre, A.; McCowen, D. Validating numerical predictions of floating offshore wind turbine structural frequencies in bladed using measured data from Fukushima Hamakaze. In Proceedings of the EERA DeepWind 2019, Trondheim, Norway, 16-18 January 2019.

12. Matsuoka, R.; Yoshimoto, H. Verification of precision concerning the design of advanced spar type structure. In Proceedings of the Japan Society of Naval Architects and Ocean Engineers, Sendai, Japan, 25-26 May 2015; Volume 20. 2015S-OS1-1.

13. Suzuki, H.; Xiong, J.; Carmo, L.H.S.; Vieira, D.P.; Mello, P.C.; Malta, E.B.; Simos, A.N.; Hirabayashi, S.; Gonçalves, R.T. Elastic response of a light-weight floating support structure of FOWT with guywire supported tower. J. Mar. Sci. Technol. 2019, 24, 1015-1028. [CrossRef]

14. Digital Solutions Bladed Engineering Feature Summary, Veritasveien; DNVGL: Høvik, Norway, 2020.

15. Jonkman, J.M.; Buhl, M.L., Jr. FAST User's Guide Updated August 2005; Technical Report; NREL/TP-500-38230; National Renewable Energy Lab. (NREL): Golden, CO, USA, 2005. 
16. Robertson, A.N.; Wendt, F.; Jonkman, J.M.; Popko, W.; Dagher, H.; Gueydon, S.; Qvist, J.; Vittori, F.; Azcona, J.; Uzunoglu, E.; et al. OC5 project phase II: Validation of global loads of the DeepCwind floating semi-submersible wind turbine. Energy Procediai 2017, 137, 38-57. [CrossRef]

17. Mohammed, K.A.; Meyer, N. Flexible multibody dynamic modeling of a floating wind turbine. Int. J. Mech. Sci. 2018, 142-143, 518-520.

18. Suzuki, H.; Shibata, H.; Fujioka, H.; Hirabayashi, S.; Ishii, K.; Kikuchi, H. Development of an analysis code of rotor-floater coupled response of a floating offshore wind turbine. In Proceedings of the ASME 32nd International Conference on Ocean, Offshore and Arctic Engineering, OMAE2013-10444, Nantes, France, 9-14 June 2013.

19. $\quad$ WAMIT $^{\circledR}$ Manual Version 7.3; WAMIT, Inc.: Chestnut Hill, MA, USA, 2019.

20. Inoue, T.; Adilah, A.; Iijima, K.; Oh, S.; Suzuki, H. Discussion on coupling effect in structural load of FOWT for condensing wind and wave bins for spectral fatigue analysis. J. Mar. Sci. Eng. 2020, 8, 937. [CrossRef]

21. Sarpkaya, T.S. Wave Forces on Offshore Structures, Reprint ed.; Cambridge University Press: Cambridge, UK, 2014.

22. Wheeler, J.D. Method for calculating forces produced by irregular waves. J. Pet. Technol. 1970, 22, 359-367. [CrossRef]

23. Det Norske Veritas. Recommended Practice DNV-RP-C205 (Environmental Conditions and Environmental Loads); DNV: Høvik, Norway, 2010.

24. Pesce, C.P.; Amaral, G.A.; Franzini, G.R. Mooring system stiffness: A general analytical formulation with an application to floating offshore wind turbines. In Proceedings of the ASME 1st International Offshore Wind Technical Conference, IOWTC2018-1040, San Francisco, CA, USA, 4-7 November 2018.

25. Stansberg, C.T.; Contento, G.; Seok, W.H.; Irani, M.; Ishida, S.; Mercier, M.; Wang, Y.; Wolfram, J.; Chaplin, J.; David, K. The Specialist Committee on Waves Final Report and Recommendations to the 23rd ITTC. In Proceedings of the 23rd ITTC, Venice, Italy, 8-14 September 2002; Volume 2, pp. 505-736. 